\title{
On the Effects of Residual Stresses Induced by Coated and Uncoated Cutting Tools with Finite Edge Radii in Turning Operations
}

\author{
J.C. Outeiro ${ }^{1}$, A.M. Dias ${ }^{1}$, I. S. Jawahir ${ }^{2}$ (1) \\ ${ }^{1}$ Division of Residual Stresses in Engineering Materials, X-Ray Diffraction Centre for Materials Research, \\ University of Coimbra, P-3004 516 Coimbra, Portugal \\ ${ }^{2}$ Machining Research Laboratory, Department of Mechanical Engineering, \\ University of Kentucky, Lexington, KY 40506, USA
}

\begin{abstract}
This paper presents an analysis of residual stresses in turning of AISI 316L and AISI 1045 steels with coated and uncoated tools having finite edge radii. An analytical predictive model, and experimental techniques involving X-ray diffraction and IR thermal imaging were used. Machining with coated tools produce higher superficial residual stresses, larger tensile layer thickness and higher residual stresses below the machined surface when using large cutting edge radii at low feed rates. This effect is correlated with the increase in the amount of heat conducted into the workpiece, and the associated generation of high tensile residual stresses and severe work-hardening.
\end{abstract}

Keywords:

Machining, Residual Stress, Cutting Edge Radius.

\section{INTRODUCTION}

With the present industry trends towards dry machining with coated tools at higher cutting speeds, the much larger amount of the thermal energy generated during machining should be dissipated by the tool, chip and workpiece. Increased thermal energy dissipated by the workpiece may result in higher residual stresses induced on the machined surface. These residual stresses may affect dramatically the performance of the machined part causing its premature failure, excessive wear, corrosion, part distortion, etc. Therefore, the state of the residual stress on the machined component represents one of the most important parameter to be considered in machining. Compressive residual stresses are usually desirable on the machined surface and the subsurface, because these stresses generally increase the fatigue life [1]

The tool coating enhances the wear resistance of the cutting tool insert, thus increasing tool-life. Significant improvements have been achieved in strength, roughness and adhesion properties of the coated carbide tool inserts, as well as on machining performance by micro-blasting of the PVD films of the coated tool [2]. Coated tools have larger cutting edge radius when compared with the uncoated tools. Also, coated tools are frequently used in practical finishing operations, at low depths of cut and low feeds. Machining operations performed at low feed (i.e., low uncut chip thickness) with tools having large cutting edge radii represents a complex geometric and work-tool material condition where the influence of the tool edge radius on the cutting process cannot be ignored.

The aim of the present study is to establish the influence of the tool cutting edge radius and the coating used in cutting tool inserts on the thermal and mechanical phenomena involving the residual stresses produced in turning operations. In order to understand the mechanisms of residual stress formation and to determine the magnitude of such residual stresses, extensive experimental and analytical work has been conducted and the results are analyzed and presented in this paper.

\section{EXPERIMENTAL AND ANALYTICAL PROCEDURES}

\subsection{Work materials, cutting tools and cutting parameters}

The experiments were carried out on a numerically controlled lathe using a bar turning process. Round bars of $140 \mathrm{~mm}$ diameter from AISI 316L and AISI 1045 steels were selected for this study. The tests were conducted using uncoated (ISO M10-M20/K05-K15) and coated (ISO P25-P45) tungsten carbide tools. The coated tools were with CVD triple layer TiC/TiCN/TiN coatings. Cutting edge radii were chosen to represent the range found in most common commercially available coated and uncoated tool inserts. The selected cutting parameters and the tool geometry according to the ISO 3002/1-1982 are summarized in Table 1. No cutting fluid was used in the machining tests.

\begin{tabular}{|l|c|c|}
\hline \multicolumn{1}{|c|}{ Cutting tool } & Uncoated & Coated \\
\hline Tool cutting edge radius $-r_{n}(\mu \mathrm{m})$ & 44 & 55 \\
\hline Tool nose radius $-r_{\varepsilon}(\mathrm{mm})$ & \multicolumn{2}{|c|}{0.8} \\
\hline Normal rake angle $-\gamma_{n}\left({ }^{\circ}\right)$ & -4.29 \\
\hline Normal flank angle $-\alpha_{n}\left({ }^{\circ}\right)$ & 4.29 \\
\hline Inclination angle cutting edge $-\lambda_{s}\left(^{\circ}\right)$ & -14 \\
\hline Tool cutting edge angle $-\kappa_{r}\left({ }^{\circ}\right)$ & 72 \\
\hline Tool minor cutting edge angle $-\kappa_{r}^{\prime}\left(^{\circ}\right)$ & 72 \\
\hline Cutting speed $-v_{c}(\mathrm{~m} / \mathrm{min})$ & $125 ; 175 ; 250$ \\
\hline Feed $-f(\mathrm{~mm} / \mathrm{rev})$ & $0.05 ; 0.1 ; 0.2$ \\
\hline Depth of cut $-a_{p}(\mathrm{~mm})$ & $1 ; 2 ; 2.5$ \\
\hline
\end{tabular}

Table 1: Tool geometry and cutting parameters.

The physical properties of the AISI 1045 and AISI 316L steels and the thermal conductivities of the uncoated and coated tool inserts are temperature $(T)$ dependent as shown in Tables 2 and 3, respectively [3-5]. 


\begin{tabular}{|c|l|}
\hline \multicolumn{2}{|c|}{ AISI 1045 } \\
\hline Density $\left(\mathrm{Kg} / \mathrm{m}^{3}\right)$ & $\rho_{w}(T)=7933.3-0.2805 \cdot T$ \\
\hline $\begin{array}{c}\text { Specific Heat } \\
(\mathrm{J} / \mathrm{Kg} \mathrm{K})\end{array}$ & $\begin{array}{l}c_{p, w}(T)=467.88+0.1888 \cdot T+ \\
0.0006 \cdot T^{2}\end{array}$ \\
\hline $\begin{array}{c}\text { Thermal } \\
\text { Conductivity } \\
(\mathrm{W} / \mathrm{m} \mathrm{K})\end{array}$ & $k_{w}(T)=40.641-0.0096 \cdot T$ \\
\hline \multicolumn{2}{|c|}{ AISI 316L } \\
\hline Density $\left(\mathrm{Kg} / \mathrm{m}^{3}\right)$ & $\rho_{w}(T)=7921-0.614 \cdot T+0.0002 \cdot T^{2}$ \\
\hline $\begin{array}{c}\text { Specific Heat } \\
(\mathrm{J} / \mathrm{Kg} \mathrm{K})\end{array}$ & $c_{p, w}(T)=440.79+0.5807 \cdot T-$ \\
\hline $\begin{array}{c}\text { Thermal } \\
\text { Conductivity } \\
(\mathrm{W} / \mathrm{m} \mathrm{K})\end{array}$ & $0.001 \cdot T^{2}+7 \times 10^{-7} \cdot T^{3}$ \\
\hline
\end{tabular}

Table 2: Physical properties of work materials [3, 4].

\begin{tabular}{|c|l|}
\hline Cutting tool & \multicolumn{1}{|c|}{ Thermal Conductivity (W/m K) } \\
\hline Uncoated tool & $\begin{array}{l}k_{t}(T)=85.932-0.0057 \cdot T- \\
6 \times 10^{-5} \cdot T^{2}+4 \times 10^{-8} \cdot T^{3}\end{array}$ \\
\hline Coated tool & $\begin{array}{l}k_{t}(T)=25.86+0.0104 \cdot T- \\
3 \times 10^{-6} \cdot T^{2}\end{array}$ \\
\hline
\end{tabular}

Table 3: Thermal conductivity of cutting tools [5].

\subsection{Experimental set-up and parameters}

Turning tests were performed on a $35 \mathrm{~kW}$ numerically controlled lathe equipped with a designed experimental set-up. For measuring the cutting forces, a Kistler type 9255B three-component piezoelectric dynamometer was used. In order to assess the temperature distribution in the deformation zone in three-dimensional cutting, an IR thermal imaging equipment (including an IR-CCD camera) was developed and applied. A detailed description of this equipment and its calibration are previously shown [6]. The measurement system was installed on the lathe as shown in Figure 1 to allow the measurement of the temperature fields in the axial and circumferential directions as shown in Figure 2.

Residual stress components were determined using a Set-X equipment, equipped with a position-sensitive detector, as shown in Figure 3. The residual stress state in the machined layers has been analyzed by the X-ray diffraction technique using the $\sin ^{2} \psi$ method. According to this method, the residual stresses were calculated from strain distribution $\varepsilon_{\phi \psi\{h k l\}}$ derived from the "measured" interreticular plane spacing and from the knowledge of the elastic radiocrystallographic constants, $S_{1\{h k l\}}$ and $1 / 2 . S_{2\{h k l}$, as described by Noyan and Cohen [7].

The parameters used in the X-ray analysis for both work materials are given in Table 4. The residual stresses were determined for the stable cutting zone (where the cutting force components and temperature distribution were stable) in the machined surface and the subsurface, in the axial (X) (along the direction of feed motion), circumferential $(Y)$ (along the direction of primary motion) and radial $(Z)$ (normal to the machined surface) directions, as shown in Figure 4. The work hardening of the material was controlled through the X-ray diffraction peak breadth width value. To determine the in-depth residual stresses profiles, successive layers of material were removed by electropolishing, to avoid the reintroduction of residual stress. Further corrections to the residual stress data were made for the volume of material removed. Due to circularity of the workpiece, a circular mask with a diameter of $2.5 \mathrm{~mm}$ was applied to limit the region for analysis. The statistical error for the calculated stresses was generally less than $50 \mathrm{MPa}$, for AISI 316L steel, and less than $30 \mathrm{MPa}$, for 1045 steel.

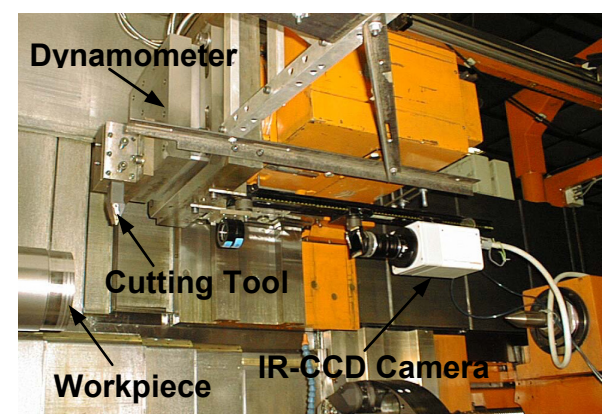

Figure 1: Measurement system on the lathe.

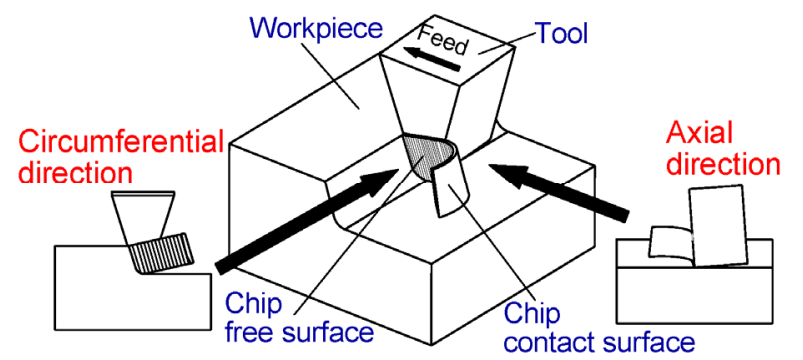

Figure 2: Schematic representation of the directions of the temperature analysis performed by the

IR thermal imaging equipment.

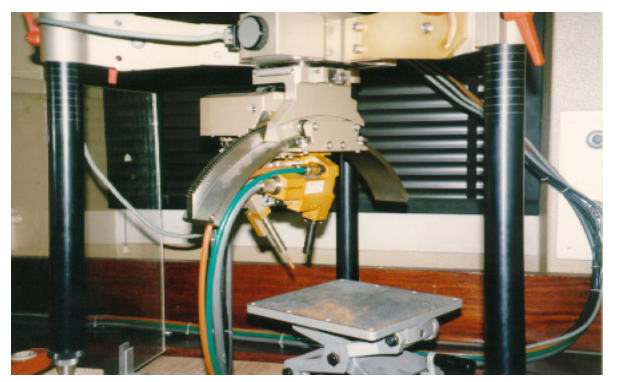

Figure 3: Set-X equipment used in the $\mathrm{X}$-ray analysis.

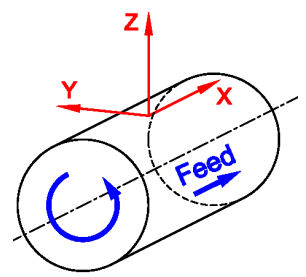

Figure 4: Directions of residual stress determination (X axial, $Y$ - circumferential and $Z$ - radial).

\begin{tabular}{|l|c|c|}
\hline Work Material & AISI 316L & AISI 1045 \\
\hline Test material phase & Fe $\gamma$ & Fe $\alpha$ \\
\hline Spot area $\left[\mathrm{mm}^{2}\right]$ & \multicolumn{2}{|c|}{5} \\
\hline $1 / 2 \mathrm{~S}_{2\{\mathrm{hk}\}}\left[\mathrm{MPa}^{-1}\right]$ & $7.03610^{-6}$ & $5.83210^{-6}$ \\
\hline$S_{1\{\mathrm{hk}\}}\left[\mathrm{MPa}^{-1}\right]$ & $-1.59710^{-6}$ & $-1.27710^{-6}$ \\
\hline Wavelengt-Radiation & $\mathrm{Mn}-\mathrm{K} \alpha$ & $\mathrm{Cr}-\mathrm{K} \alpha$ \\
\hline Filter & $\mathrm{Cr}$ & $\mathrm{Va}$ \\
\hline Bragg angle 2 $\theta\left[^{\circ}\right]$ & $\begin{array}{c}152,26 \\
(\mathrm{hkl})=(311)\end{array}$ & $\begin{array}{c}156,33 \\
(\mathrm{hkl})=(211)\end{array}$ \\
\hline
\end{tabular}

Table 4: Parameters used in the $\mathrm{X}$-ray analysis. 


\subsection{Analytical model and parameters}

An analytical model, developed in earlier investigation [8], was used to study the three-dimensional cutting process using tools with major and minor cutting edges connected by a corner radius. This model is also applied to particular cutting situations where the uncut chip thickness is of the same order of the tool cutting edge radius. Figure 5 shows the flowchart of the general procedure used to calculate the temperatures and heat partition in the deformation zone.

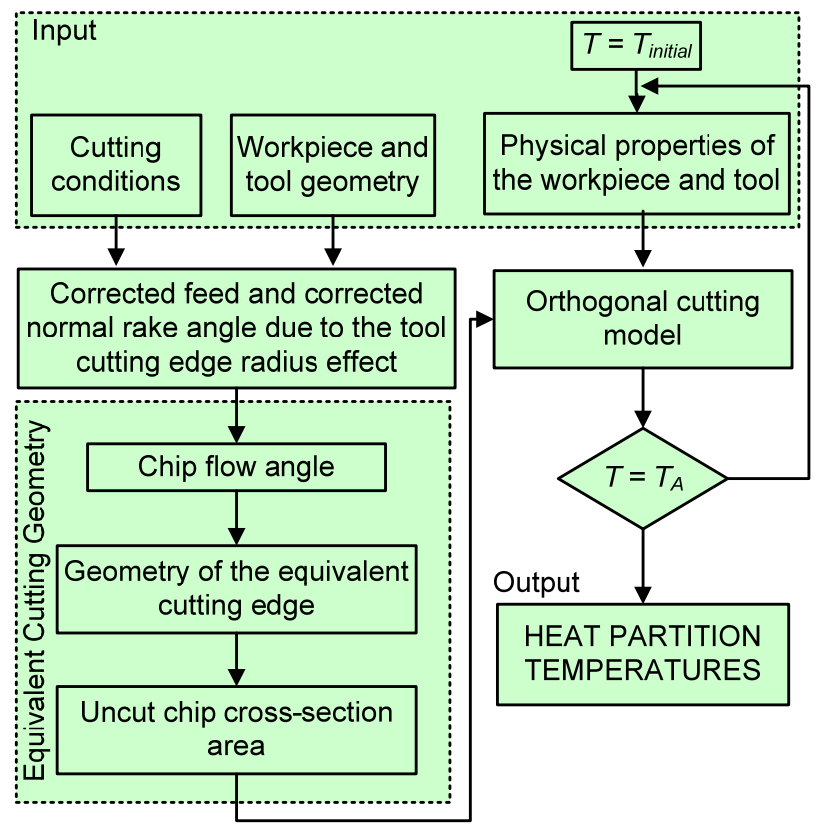

Figure 5: Flowchart of the analytical model [8].

The analytical model includes three main steps:

1. Determination of the corrected feed, $f^{\prime}$, and the corrected normal rake angle, $\gamma_{n}^{\prime}$, due to the tool cutting edge radius effect. The finite radius of the cutting tool produces a ploughing effect in machining [9]. As the tool cutting edge radius increases, ploughing competes directly with cutting. In this work it is assumed that the total uncut chip thickness, $h_{r}$, is composed of the actual uncut chip thickness, $h_{1}$, and the layer to be burnished, $h_{p}$, by the rounded part of the cutting edge adjacent to the tool flank face $\left(h_{r}=h_{1}+h_{p}\right)$. Because the actual uncut chip thickness, $h_{1}$, is smaller than the total uncut chip thickness, $h_{r}$, the cutting feed corresponding to the actual uncut chip thickness can be thought of as the apparent cutting feed, $f^{\prime}$ which is smaller than the real cutting feed, $f$. As seen, the apparent cutting feed, $f^{\prime}$ can be calculated according to Equation (1). The use of uncut chip thickness of the same order of the tool cutting edge radius also induces changes in the actual or corrected tool rake angle. We propose the method shown in Figure 6 to calculate this rake angle and given by Equation (2).

$$
f^{\prime}=\frac{h_{1}}{\sin \left(\kappa_{r}\right)}=f-\frac{h_{p}}{\sin \left(\kappa_{r}\right)}
$$

$$
\gamma_{n}^{\prime}=\left\{\begin{array}{c}
\arcsin \left(\frac{h_{r}}{r_{n}}-1\right) \quad \text { if } \quad h_{r}<r_{n} \cdot\left(1+\sin \gamma_{n}\right) \\
\gamma_{n} \text { if } \quad h_{r} \geq r_{n} \cdot\left(1+\sin \gamma_{n}\right)
\end{array}\right.
$$

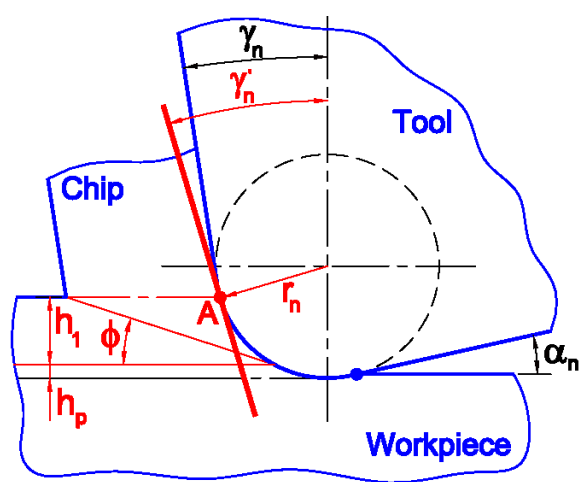

Figure 6: Model of the rounded tool cutting edge.

2. Determination of the equivalent cutting geometry. To make analytical studies of three-dimensional cutting process easier, some simplifications of the real cutting process are needed. One of the common simplifications is the introduction of the concept of the equivalent cutting edge. This cutting edge replaces the major and minor cutting edges and the tool nose in the manner shown in Figure 7 [8, 10]. This equivalent cutting edge is defined as a straight line that connects the end of the major and minor cutting edges as shown in Figure 7. Once the equivalent cutting edge is constructed, the direction of chip flow is assumed to be perpendicular to this edge. As any cutting edge, this edge is characterized by an equivalent geometry including a set of equivalent angles: tool rake angle, $\gamma_{n}^{e q}$, tool flank angle, $\alpha_{n}^{e q}$, tool cutting edge inclination angle of the cutting edge, $\lambda_{s}^{e q}$, and tool cutting edge angle, $\kappa_{r}^{e q}$. In turn, the determination of the equivalent cutting geometry includes the following three steps: (i) Determination of the chip flow angle, $\eta_{c}$, using the Colwell model, as shown in Figure 7, (ii) Determination of the geometry of the equivalent cutting edge $\left(\gamma_{n}^{e q}, \alpha_{n}^{e q}, \lambda_{s}^{e q}, \kappa_{r}^{e q}\right)[8,10]$, and (iii) Determination of the uncut chip cross-section area as the product of the true uncut chip width, $b_{1 T}$ and true uncut chip thickness, $h_{1 T}$ as described previously [11]. By adopting these simplifications, the actual threedimensional cutting can be represented by orthogonal cutting, thus the orthogonal cutting theory can be applied to estimate the heat partition and the temperatures generated.

3. Using the equivalent cutting geometry and the physical properties of the workpiece and the tool, an orthogonal cutting model was applied to predict the temperatures and heat partition in the deformation zone. A detailed description of this model has been presented previously [11], and the relevant heat partition method used in the present work taken from this model is now summarized as follows:

Since practically all of the mechanical energy associated with chip formation is converted into thermal energy, the heat balance equation is of prime concern in metal cutting studies [11]. This equation can be written as 


$$
F_{c} v_{c}=Q_{\Sigma}=Q_{c}+Q_{w}+Q_{t}
$$

where $F_{c}$ is the cutting force, $\mathrm{N} ; v_{c}$ is the cutting speed, $\mathrm{m} / \mathrm{s} ; Q_{\Sigma}$ is the total thermal energy generated in the cutting process, $\mathrm{J} / \mathrm{s} ; Q_{c}$ is the thermal energy transported by the chip, J/s; $Q_{w}$ is the thermal energy conducted into the workpiece, $\mathrm{J} / \mathrm{s} ; Q_{t}$ is the thermal energy conducted into the tool, J/s.

Using the orthogonal cutting model referred above, the following equations were obtained [11]:

- Thermal energy transported by the chip $\left(Q_{c}\right)$

$$
\begin{aligned}
Q_{c}= & \frac{\tau_{f} h_{1 T} b_{1 T} v_{c}}{B}\left[\varphi_{1} \varphi_{2} \operatorname{erf} \sqrt{\frac{P e B}{4}}+\cdots\right. \\
& \left.\cdots B \varphi_{3} \frac{\cos \gamma_{n}^{e q}+\sin \gamma_{n}^{e q}-B\left(\cos \gamma_{n}^{e q}-\sin \gamma_{n}^{e q}\right)}{\cos \gamma_{n}^{e q}+B \sin \gamma_{n}^{e q}}\right]
\end{aligned}
$$

where,

$\varphi_{1}=1-\frac{2}{P e B}+\frac{1.125}{\sqrt{P e B}} \frac{\exp \left(-\frac{P e B}{4}\right)}{\operatorname{erf} \sqrt{\frac{P e B}{4}}}$

$$
\varphi_{2}=\frac{1}{1+\frac{0.225 F D^{0.3}}{P e\left(1-\sin \gamma_{n}^{e q}\right)^{0.4}}}
$$

$$
\varphi_{3}=\frac{1}{1+\frac{0.325 F D^{0.3}\left(1-\sin \gamma_{n}^{e q}\right)^{0.25}}{\sqrt{P e}}}
$$

- Thermal energy conducted into the tool $\left(Q_{t}\right)$

$$
Q_{t}=\frac{0.54 \tau_{f} h_{1 T} b_{1 T} v_{c} F^{0.88} D^{0.26} M^{0.47} E^{0.27} e r f^{0.35} \sqrt{\frac{P e B}{4}}}{P e^{0.615}\left(1-\sin \gamma_{n}^{e q}\right)^{0.5} \sin ^{0.15} \alpha_{n}^{e q} B^{0.72}}
$$

- Thermal energy conducted into the workpiece $\left(Q_{w}\right)$

$$
\begin{aligned}
& Q_{w}=\tau_{f} h_{I T} b_{I T} v_{c} M\left[\frac{0.665 \varphi_{4} \operatorname{erf} \sqrt{\frac{P e B}{4}}}{\sqrt{P e B}}+\cdots\right. \\
& \left.\ldots \frac{0.625 E \varphi_{5} B^{1.5}}{\sin ^{0.55} \alpha_{n}^{e q}}\right]
\end{aligned}
$$

where,

$$
\begin{gathered}
\varphi_{4}=\frac{1}{1+\frac{0.27 F D^{0.3} E^{0.3}}{\sqrt{P e} \sin ^{0.15} \alpha_{n}^{e q}}} \\
\varphi_{5}=\frac{1}{1+\frac{0.35 F D^{0.3} \sin ^{0.1} \alpha_{n}^{e q}}{\sqrt{P e} E^{0.2}}}
\end{gathered}
$$

$\tau_{f}$ is the shear stress at fracture of the work material and the parameters $\mathrm{Pe}, B, D, E, F$ and $M$ are previously described [11].

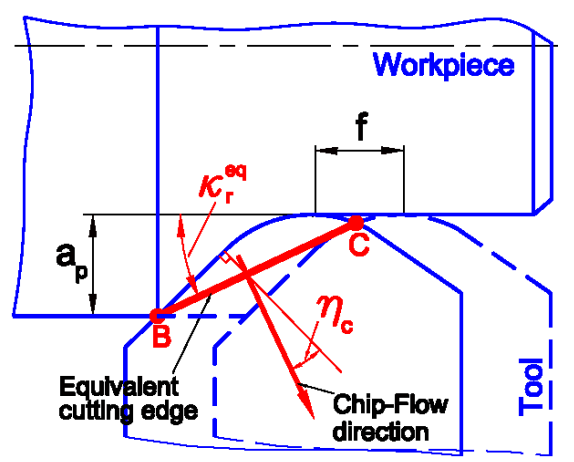

Figure 7: Definition of equivalent cutting edge.

\section{RESULTS AND DISCUSSION}

\subsection{Residual stress tensor analysis}

The nine components of the residual stress tensor determined on the machined surface and the subsurface at different depths show that the stress component normal to the surface $\left(\sigma_{z}=0\right)$ was negligible, due to the low indepth penetration of the X-rays [12]. Moreover, our analysis of the residual stress tensors for all cutting parameters and for both work materials used in this study allowed us to conclude that the shear stress components $\tau_{x z}$ and $\tau_{y z}$ can be negligible when they were compared with the shear stress component $\tau_{x y}$. Moreover, $\tau_{x z}$ and $\tau_{y z}$ components for some cutting parameters were of the same order as the error of the measurement. Therefore, the three-axial state of stress is reduced to a more simplified biaxial state of stress.

\subsection{Distributions of residual stresses due to the coated and uncoated cutting tools}

For the range of the cutting conditions presented in Table 1 , tensile circumferential residual stresses $\left(\sigma_{y}\right)$ were found at the machined surface, reaching a maximum value of $615 \mathrm{MPa}$ for the $316 \mathrm{~L}$ steel, and $240 \mathrm{MPa}$ for the 1045 steel. Concerning to the axial residual stresses $\left(\sigma_{x}\right)$, their magnitudes at the machined surface were always lower compared to the magnitudes of the circumferential residual stresses. They were compressive or tensile on the surface depending on the cutting conditions. For the 1045 steel, they are almost compressive, reaching a maximum of the order of $-205 \mathrm{MPa}$, while for the 316L steel they were almost tensile, reaching a maximum of $320 \mathrm{MPa}$. Figures 8 and 9 show the in-depth residual stress profiles for both work materials on the machined surface and the subsurface generated by the coated and the uncoated cutting tools. These figures show that for both, 1045 and $316 \mathrm{~L}$ steels, the residual stress level in axial and circumferential directions changes continuously in-depth down to a certain maximum value in the compressive region and then gradually increases, stabilizing at the level corresponding to that found in the work material before machining (0 MPa for the $316 \mathrm{~L}$ steel and $-100 \mathrm{MPa}$ for the 1045 steel). High compressive residual stresses are found in the subsurface in the axial direction, the maximum value of which being higher for the 316L steel than for the 1045 steel. The actual depth at which the circumferential stresses reach zero can be thought as the thickness of the layer affected by tensile residual stresses. This thickness seems to be slightly higher for the 316L steel than for the 1045 steel. Figures 8 
and 9 also show the in-depth residual stress profiles generated by the coated and the uncoated tools. These figures show that machining with coated tools when compared with the uncoated tools results in: (i) higher circumferential residual stresses; (ii) higher thickness of the tensile layer in the circumferential direction; and (iii) higher residual stresses (maximum) below the machined surface in the axial direction. This maximum is also shifted further from the machined surface (see Figure 9).

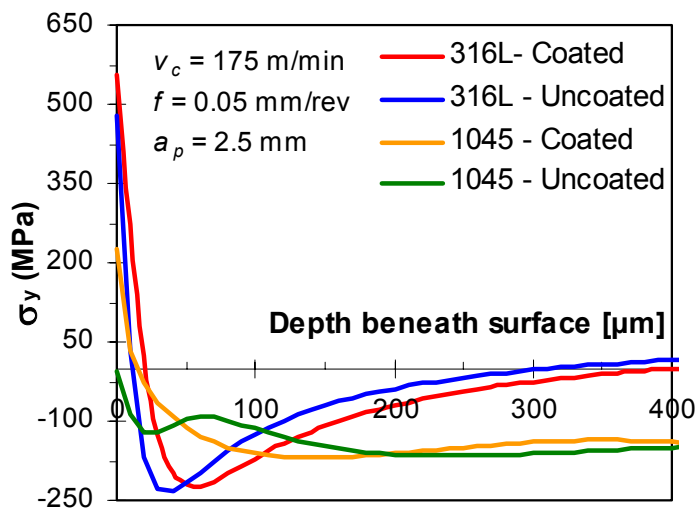

Figure 8: In-depth profiles of the circumferential residual stress $\left(\sigma_{y}\right)$ for $316 \mathrm{~L}$ steel and 1045 steel generated in machining with coated and uncoated cutting tools.

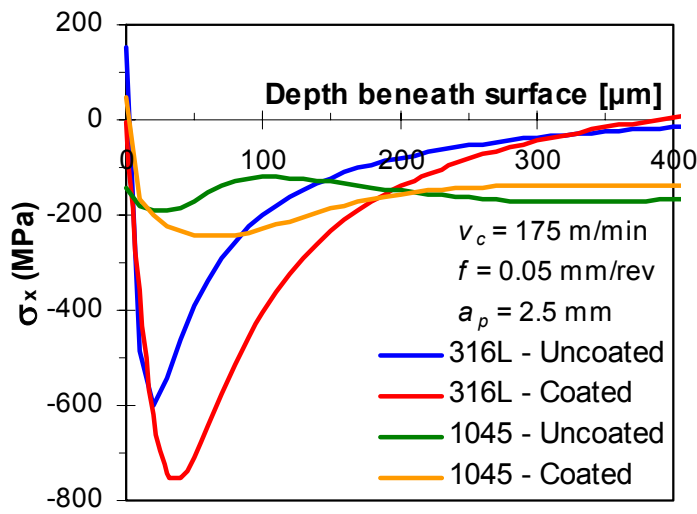

Figure 9: In-depth profile of the axial residual stress $\left(\sigma_{x}\right)$ for 316L steel and 1045 steel, generated in machining with coated and uncoated cutting tools.

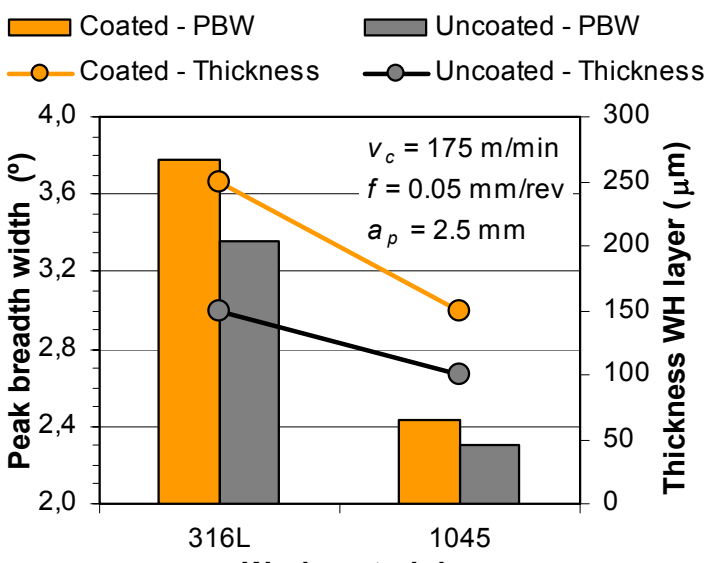

Work material

Figure 10: Peak breadth width (PBW) and thickness of the work hardened $(\mathrm{WH})$ layer when machining $316 \mathrm{~L}$ steel and 1045 steel using coated and uncoated cutting tools.
The peak breadth width is an important parameter obtained by X-ray diffraction, and like the microhardness, this can be used to estimate the amount of material's work hardening [12]. Figure 10 shows for both work materials the peak breadth width at the machined surface and the thickness of the work hardening layer generated by the coated and uncoated tools. This figure shows that the coated tool causes a higher work hardening compared to the uncoated tool, as well as a greater thickness of the work hardening layer, with this effect becoming more significant for the $316 \mathrm{~L}$ steel, especially due to its higher strain rate sensitivity.

\subsection{Thermal and mechanical phenomena and their} correlation with the residual stresses

Table 5 shows that, for the case of machining of 1045 steel under the same cutting conditions, the cutting forces are slightly higher for the uncoated tool, and thus this tool generates higher total thermal energy, $Q_{\Sigma}$, during machining. As a consequence, the use of a coated tool results in lower temperature on the chip compared to the uncoated tool, as shown in Table 5 and Figure 11. This result can be due to the less severe frictional conditions when machining with the coated tool.

Figure 11 also shows that the tool temperature is much lower in the case of the coated tool due to lower therma conductivity of the coating layer [5]. Unfortunately, it was not possible to assess the temperature on the machined surface due to the difficulties in measuring the temperature on this surface with adequate accuracy [6].

\begin{tabular}{|l|c|c|}
\hline Cutting speed & $\mathbf{1 7 5} \mathbf{~ m} / \mathbf{m i n}$ & $\mathbf{2 5 0} \mathbf{~ m} / \mathbf{m i n}$ \\
\hline$F_{C}-$ Uncoated tool & $535 \mathrm{~N}$ & $540 \mathrm{~N}$ \\
\hline$F_{C}-$ Coated tool & $505 \mathrm{~N}$ & $480 \mathrm{~N}$ \\
\hline$Q_{\Sigma}-$ Uncoated tool & $1560 \mathrm{~J} / \mathrm{s}$ & $2250 \mathrm{~J} / \mathrm{s}$ \\
\hline$Q_{\Sigma}-$ Coated tool & $1473 \mathrm{~J} / \mathrm{s}$ & $2000 \mathrm{~J} / \mathrm{s}$ \\
\hline$T_{c f}-$ Uncoated tool & $610^{\circ} \mathrm{C}$ & $613^{\circ} \mathrm{C}$ \\
\hline$T_{c f}-$ Coated tool & $546^{\circ} \mathrm{C}$ & $550^{\circ} \mathrm{C}$ \\
\hline
\end{tabular}

Table 5: Cutting force $\left(F_{c}\right)$, total thermal energy $\left(Q_{\Sigma}\right)$ and maximum temperature at the chip free surface $\left(T_{c f}\right)$ in machining of 1045 steel.

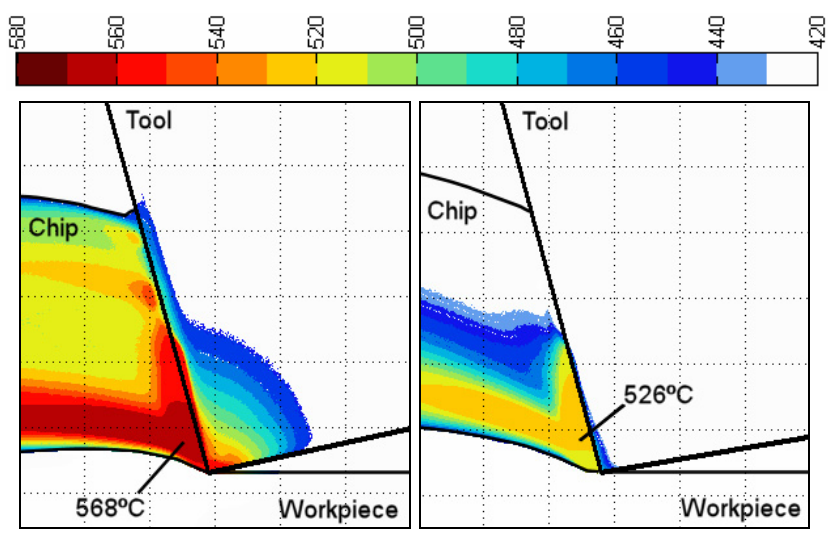

(a)

(b)

Figure 11: Thermal maps on the chip and tool measured by the IR thermal imaging equipment positioned in the axial direction, during machining of 1045 steel with

(a) uncoated, and (b) coated tools.

In order to quantify the amount of heat conducted into the workpiece, the analytical model was applied for three cases shown in Figure 12. Case 1 represents an uncoated tool with a cutting edge radius of $44 \mu \mathrm{m}$. Case 2 also represents an uncoated tool, but with a larger cutting edge 
radius $(55 \mu \mathrm{m})$. Case 3 represents a coated tool with CVD coating of $\mathrm{TiC} / \mathrm{TiCN} / \mathrm{TiN}$, and with the same cutting edge radius as in Case $2(55 \mu \mathrm{m})$.

The results obtained from these three cases are shown in Table 6, when machining the 1045 steel at a cutting speed of $175 \mathrm{~m} / \mathrm{min}$, feed of $0.05 \mathrm{~mm} / \mathrm{rev}$ and depth of cut of 2.5 $\mathrm{mm}$. This table shows that for the same cutting parameters an increase in the cutting tool edge radius (Case $1 \rightarrow$ Case 2) leads to a reduction in the amount of heat transported by the chip $\left(Q_{c}\right)$ while a reduction in the heat conducted into the tool $\left(Q_{t}\right)$ was observed when the coated tool was used (Case $2 \rightarrow$ Case 3 ). The combined effect of the increase in the cutting tool edge radius and coating (Case $1 \rightarrow$ Case 3 ) leads to an increase in the amount of the heat conducted into the workpiece $\left(Q_{w}\right)$. Similar results were obtained for the $316 \mathrm{~L}$ steel. Thus, it is evident that although the coated tool generated slightly less total thermal energy when compared to the uncoated tool, more heat is conducted into the workpiece when the coated tool is used.

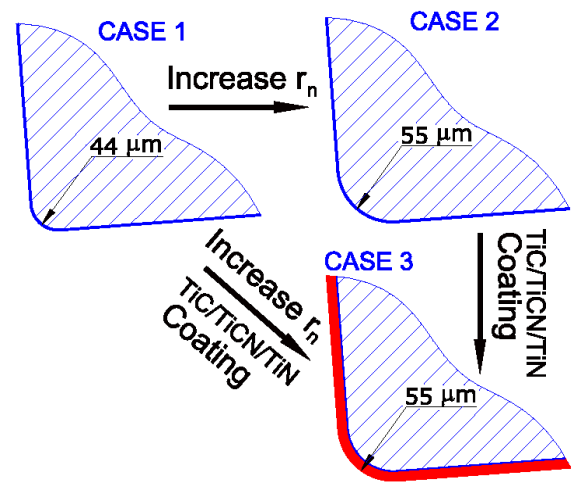

Figure 12: Three cases of cutting edge conditions and coatings used in the modelling and experimental work.

\begin{tabular}{|c|c|c|c|}
\hline $\mathbf{1 0 4 5}$ steel & $\boldsymbol{Q}_{\boldsymbol{c}} \mathbf{( \% )}$ & $\boldsymbol{Q}_{\boldsymbol{w}} \mathbf{( \% )}$ & $\boldsymbol{Q}_{\boldsymbol{t}} \mathbf{( \% )}$ \\
\hline Case 1 & 63.7 & 22.7 & 13.6 \\
\hline Case 2 & 56.3 & 27.9 & 15.8 \\
\hline Case 3 & 61.1 & 31.2 & 7.7 \\
\hline Case 1 $\rightarrow$ Case 2 & -7.3 & +5.2 & +2.1 \\
\hline Case 2 $\rightarrow$ Case 3 & +4.8 & +3.3 & -8.1 \\
\hline Case 1 $\rightarrow$ Case 3 & -2.5 & +8.5 & -6.0 \\
\hline
\end{tabular}

Table 6: Heat partition during machining of 1045 steel.

Recent results obtained by FEM [13] show that the superficial residual stresses increase both with the tool cutting edge radius and the coating. The increase in the thermal energy conducted into the workpiece is probably the main cause for the higher values of the superficial residual stress and thickness of the tensile layer when machining with coated tools having a TiC/TiCN/TiN CVD coating. In order to balance the high superficial residual stress, the maximum residual stresses below the machined surface have to become more compressive.

\section{SUMMARY}

The residual stresses induced by coated and uncoated tungsten carbide tools with finite edge radii in turning of AISI 316L and AISI 1045 steels were investigated by the $X$-ray diffraction. The results show that machining with coated tools, using a particular CVD coating $\mathrm{TiC} / \mathrm{TiCN} / \mathrm{TiN}$, produces higher superficial residual stresses, larger tensile layer thickness, higher residual stresses below the machined surface and higher work hardening in comparison with machining with uncoated tools, when large edge radii are used at low feed rates.

In order to quantitatively evaluate variation of residual stresses and work hardening between coated and uncoated cutting tools, the temperature distribution and the forces were measured during the machining tests and an analytical model was used to study the heat partition in turning. The results show that although the coated tool generated slightly less total thermal energy when compared to the uncoated tool, more heat is conducted into the workpiece when the coated tool is used. As a result, high temperatures and thermally affected layers are produced on the machined surface. This may justify the difference in the residual stresses and work hardening between the coated and uncoated cutting tools.

\section{REFERENCES}

[1] Matsumoto Y., Hashimoto F., Lahoti G., 1999 , Surface Integrity Generated by Precision Hard Turning, Annals of the CIRP, 48/1: 59-62.

[2] Bouzakis K.-D., Skordaris G., Mirisidis I., Mesomeris G., Michailidis N., Pavlidou E., Erkens G., 2005, Micro-blasting of PVD Films, an Effective Way to Increase the Cutting Performance of Coated Cemented Carbide Tools, Annals of the CIRP, 54/1: 95-98.

[3] Davis J.R., 1998, Metals Handbook Desk Edition, 2nd Edition, ASM.

[4] Lacombe P., Baroux B., Beranger G., 1990, Les Aciers Inoxidables, Les Editions de Physique, Les Ulis, France.

[5] Jawahir I.S., Van Luttervelt C.A., 1993, Recent Developments in Chip Control Research and Applications, Annals of the CIRP, 42/2: 659-693.

[6] Outeiro J.C., Dias A.M., Lebrun J.L., 2004, Experimental Assessment of Temperature Distribution in Three-Dimensional Cutting Process, Machining Science and Technology, 8/3: 357-376.

[7] Noyan I.C., Cohen J.B., 1987, Residual Stress Measurement by Diffraction and Interpretation, Society for Experimental Mechanics Ed., SpringerVerlag, New York.

[8] Outeiro J.C., Astakhov V.P., 2005, The Role of the Relative Tool Sharpness in Modelling of the Cutting Process, Proc. 8th CIRP International Workshop on Modeling of Machining Operations, Chemnitz, Germany: 517-523.

[9] Basuray P.K., Misra B.K., Lal G.K., 1977, Transition from Ploughing to Cutting during Machining with Blunt Tools, Wear, 43: 341-349.

[10] Arsecularatne J.A., Mathew P., Oxley P.L.B., 1995, Prediction of Chip Flow Direction and Cutting Forces in Oblique Machining with Nose Radius Tools, Proceedings of the Institution of Mechanical Engineers, Part B: Journal of Engineering Manufacture, 209: 305-315.

[11] Astakhov V.P., 1998, Metal Cutting Mechanics, CRC Press, Boca Raton, Florida, USA.

[12] Lu J., 1996, Handbook of Measurement of Residual Stresses, Society for Experimental Mechanics Ed., The Fairmont Press.

[13] Outeiro J.C., Umbrello D., M'Saoubi R., 2005, Experimental and numerical modelling of the residual stresses induced in orthogonal cutting of AISI 316 L steel, International Journal of Machine Tools and Manufacture (in press). 